\title{
Characterization of (Polyvinyl alcohol-polyacrylamide -Pomegranate Peel ) Compositeso as Biocomposites Materials
}

\author{
Ahmed Hashim*, Maithem Husaien, Jameel Habeeb Ghazi, Hussein Hakim \\ University of Babylon, Iraq \\ Corresponding Author: ahmed taay@yahoo.com
}

Copyright (C) 2013 Horizon Research Publishing All rights reserved.

\begin{abstract}
In this paper, samples of composites consisting of polyvinyl alcohol- polyacrylamide and pomegranate peel were prepared by using the casting method. The polymers composites which the prepared have many applications. The concentrations of pomegranate peel are (0, 2,4 and 6) wt. $\%$. The results show that the optical properties of polymer matrix are changed with the increase of the pomegranate peel concentrations
\end{abstract}

Keywords Optical Properties, Polyacrylamide, Pomegranate Peel

\section{Introduction}

Composite materials have been increasingly used for various other technical tasks, where it is beneficial to apply lightweight construction materials which have high strength and stiffness characteristics. The favorable specific properties of fiber reinforced polymer composites are based on the low density of the matrix resins used, and the high strength of the embedded fibers. Fabrication of fiber reinforced polymer composites relatively low cost. These composites are considered as replacements for metal materials. Polymer matrix reinforced by fiber is probably the most commonly used form of composites in structural application, such as air craft's, boats, automobiles[1]. A single material may not meet all the requirements necessary for a potential filler. Since the final properties of the composites are controlled by the properties and proportion of the component materials, the choice of the filler plays a very important role in polymer composites [2]. The development of polymer systems with high ionic conductivity is one of the main objectives in polymer research. This is because of their potential applications as electrolytes in solid-state batteries, fuel cells, electrochemical display devices/smart windows, photo electrochemical cells etc., due to their high conductivity, high energy density, wide electrochemical stability and easy process ability. The main advantages of polymer electrolytes are their mechanical properties, ease of fabrication of thin films of desirable sizes and their ability to form proper electrode/electrolyte contact in electrochemical devices [3].

\section{Experimental Part}

The materials used in this work are polyacrylamide and polyvinyl alcohol as a matrix and pomegranate peel as filler. The polyacrylamide and polyvinyl alcohol were dissolved in distill water with percentage ( $25 \mathrm{wt} . \%$ is polyacrylamide and $75 \mathrm{wt} . \%$ is polyvinyl alcohol). the pomegranate peel is added to matrix with different concentrations are $(0,2,4$ and 6$)$ wt.\% . The casting technique is used to preparation the samples. The optical properties were measured by using UV/1800/Shimadzu spectrophotometer.

\section{Results and Discussion}

The absorbance of composites was measured in the wavelength range (200-800)nm. Fig.1: shows that the absorbance of composites is increased with the increase of the pomegranate peel concentration, this behavior attributed to particles which absorb the incident light [4].



Figure 1. The variation of optical absorbance of composite with wavelength 
The absorption coefficient $(\alpha)$ is defined by $[4,5]$ :

$$
\alpha=2.303 \mathrm{~A} / \mathrm{d} \ldots \ldots
$$

Where A: is the absorbance of sample and $\mathrm{d}$ : is the sample thickness.

Figure (2) represents the variation of absorption coefficient of composites of different concentration of filler with the photon energy.

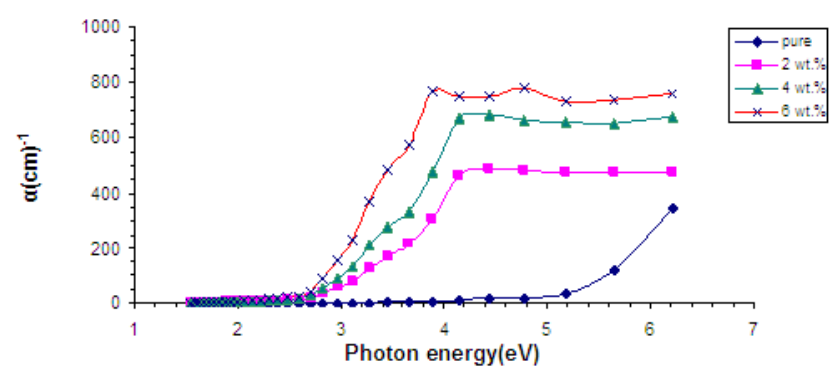

Figture 2. The absorption coefficient of composite with various photon energy

From the figure, the absorption coefficient of composites less than $10^{4} \mathrm{~cm}^{-1}$ which refer to the composites have indirect energy band gap which calculated by[6]:

$$
\alpha h v=B\left(h v-E_{g}\right)^{r}
$$

Where: hv is the photon energy, $\mathrm{B}$ is a constant, $\mathrm{E}_{\mathrm{g}}$ is the energy band gap, $\mathrm{r}=2$ and 3 for allowed and forbidden indirect transition. The increase of the concentration of filler is produced increase of the localized states in the forbidden gap which decreases the optical energy gap [6] as shown in figures(3 and 4).

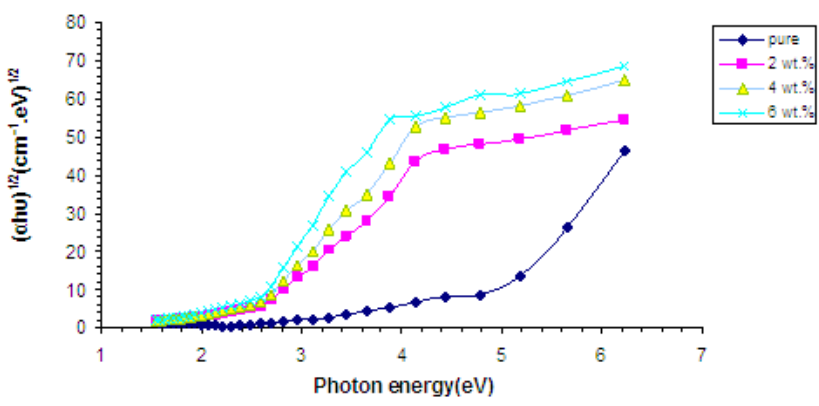

Figure 3. The relationship between $(\mathrm{a} \mathrm{hu})^{1 / 2}\left(\mathrm{~cm}^{-1} \mathrm{eV}\right)^{1 / 2}$ and photon energy of composites

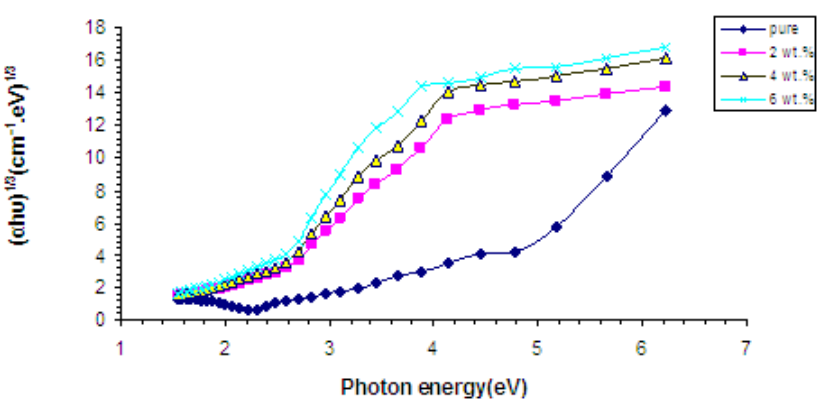

Figure 4. The relationship between $(a \mathrm{hu})^{1 / 3}\left(\mathrm{~cm}^{-1} \mathrm{eV}\right)^{1 / 3}$ and photon energy of composites
The refractive index (n) of the composits is defined [7]:

$$
\mathrm{n}=\left(1+\mathrm{R}^{1 / 2}\right) /\left(1-\mathrm{R}^{1 / 2}\right) \ldots \ldots
$$

Where $\mathrm{R}$ is reflectance

The extinction coefficient $(\mathrm{k})$ of composites is calculated by [7]:

$$
\mathrm{k}=\alpha \lambda / 4 \pi \ldots \ldots
$$

The behavior of refractive index and extinction coefficient of the composites with photon energy are shown in figures ( 5 and 6 ). The refractive index of matrix of polymers is increased with the increase of the concentration of the pomegranate peel as result to increase the scattering of light because increase the density of polymers with increase the concentration of the pomegranate peel. The extinction coefficient of composite polymer is increased with the increase of the percentages of potassium chloride as result to the increase the loss of energy of incident light by the particles of composites $[7,8]$.

The dielectric constants (real $\left(\varepsilon_{1}\right)$ and imaginary $\left(\varepsilon_{2}\right)$ parts) are defined by[9]:

$$
\begin{gathered}
\varepsilon_{1}=\mathrm{n}^{2}-\mathrm{k}^{2} \\
\varepsilon_{2}=2 \mathrm{nk}
\end{gathered}
$$

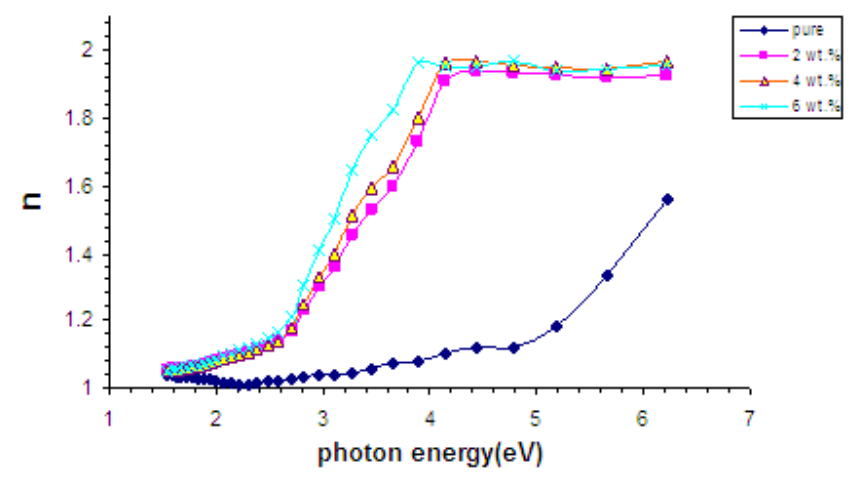

Figure 5. The relationship between refractive index of composite with photon energy

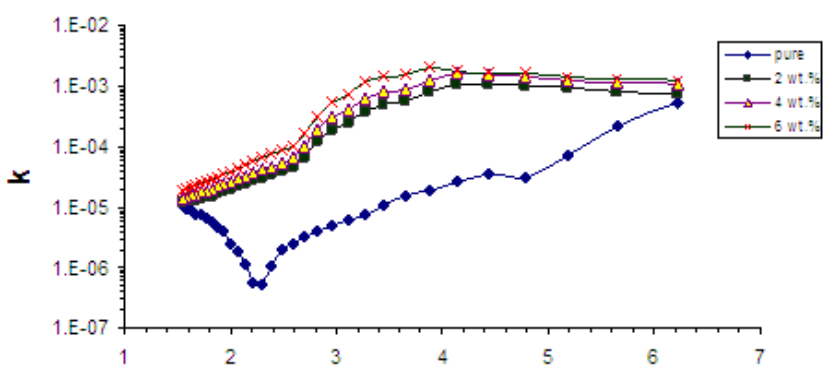

Figure 6. The extinction coefficient of composite with various photon energy

Figures (7) and (8) show the variation of real and imaginary parts of dielectric constants of composites with different concentration of filler. From these figures, the real and imaginary parts of dielectric constants are increased with the increase of the concentration of the pomegranate peel which attributed to increase the scattering and loss of 
energy of light in the material which increase the refractive index and extinction coefficient [9].



Figure 7. The variation of real part of dielectric constant of composite with photon energy

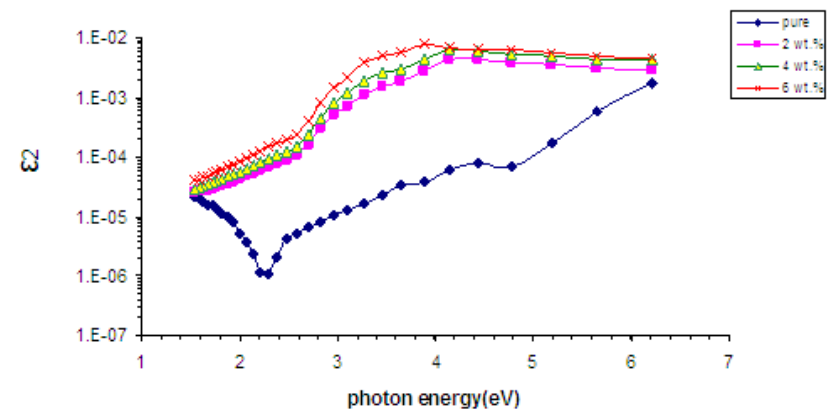

Figure 8. The variation of imaginary part of dielectric constant of composite with photon energy

\section{Conclusions}

1. The absorbance of the polyacrylamide- polyvinyl alcohol is increased with the increase of the pomegranate peel concentration.

2. The absorption coefficient, extinction coefficient, refractive index and real and imaginary dielectric constants the polyacrylamide- polyvinyl alcohol are increasing with the increasing of the weight percentages of pomegranate peel.

3. The indirect energy band gap of the polyacrylamidepolyvinyl alcohol is decreased with the increasing of the pomegranate peel concentration.

\section{REFERENCES}

[1] K.Devendra1, T. Rangaswamy, 2012, Evaluation of Thermal Properties of E-Glass/ Epoxy Composites Filled By Different Filler Materials, International Journal Of Computational Engineering Research, Vol. 2, No. 5, P. 17081714.

[2] V. S. Vinod, Siby Varghese, Rosamma Alex, Baby Kuriakose, 2000, Effect of Aluminum Powder on Filled Natural Rubber Composites, Rubber Chemistry and Technology, Vol. 74, P. 236-248.

[3] U. Sasikala, P. Naveen Kumar, V.V.R.N.Rao and A. K. Sharma, 2012, "structural, electrical and parametric studies of PEO based polymer electrolyte for battery applications", international journal of engineering science \& advance technology, Vol. 2, No. 33, PP. 722-730.

[4] Ahmad A.H., Awatif A.M. and Zeid Abdul-Majied N., 2007, “J. of Eng. \&Technology”, Vol.25, No.4, PP 558-568.

[5] E.M. Abdelrazek, A.M. Abdelghany, A.H. Oraby and G.M. Asnag, 2012, " Investigation of Mixed Filler Effect on Optical and Structural Properties of PEMA Films", International Journal of Engineering \& Technology IJETIJENS Vol.12 No,4, PP. 98-102.

[6] Hamed M. Ahmad, Sabah H. Sabeeh, Sarkawt A. Hussen, 2012, "Electrical and Optical Properties of PVA/LiI Polymer Electrolyte Films", Asian Transactions on Science and Technology, Vol. 1, No.6, PP.16-20.

[7] Tariq J. Alwan, 2010, "Refractive Index Dispersion and Optical Properties of Dye Doped Polystyrene Films", Malaysian Polymer Journal, Vol. 5, No. 2, PP. 204-213. A. Rawat, H. Mahavar, S. Chauhan, A. Tanwarand and P.Singh, 2012, " optical band gap of polyvinyl pyrrolidone/ polyacrilamide bland thin films", Indian journal of pure applied physics, Vol. 50, PP. 100- 104.

[8] E.I. Ugwu, 2006, " Optical Properties of Iron Halide (FeCl2) Thin Film Deposited Using Solution Growth Technique (SGT)", The Pacific Journal of Science and Technology, Vol. 7, No., 2, PP. 97-102.

[9] Nahida. J. H. \& Marwa. R. F, 2011, Study of the Optical Constants of the PMMA/PC Blends, Eng. \& Tech. Journal ,Vol.29, No.4, PP. 698- 708. 